\title{
A structured and individualised safety programme reduced falls in high risk nursing home patients
}

Ray WA, Taylor JA, Meador KG, et al. A randomized trial of a consultation service to reduce falls in nursing homes. JAMA 1997 Aug 20;278:557-62.

\section{Objective}

To determine whether a multicomponent individualised intervention programme designed to modify suboptimal safety practices prevents falls and associated injuries in high risk patients in nursing homes.

\section{Design}

1 year, randomised controlled trial.

\section{Setting}

14 nursing homes (7 pairs) in Tennessee, USA, matched for number of beds. Nursing homes had 80-250 beds, had no specialised psychiatric or short stay skilled nursing care, used moderate to high levels of psychotropic drugs, and had administrative stability (no current vacancy and $\leqslant 3$ turnovers in administrative positions during the previous $18 \mathrm{mo}$ ).

\section{Patients}

1933 patients lived in the 14 nursing homes. 499 patients (232 in study homes and 267 in control homes) were assessed by the study team to be at high risk for falls and were included in the study. Exclusion criteria were age $<65$ years, anticipated residence $<6$ months, being bed bound, having no falls in the previous year, and no individual safety problem.

\section{Intervention}

The intervention team (nurses, occupational therapists, psychiatrists) assessed each patient on 4 areas: environmental and personal safety, wheelchair maintenance and safety, psychotropic drug use, and transfer and ambulation. Recommendations were made for each patient. At each home, a falls coordinator was appointed who worked with the intervention team, and, when appropriate, with the resident, the resident's family, facility administration, and staff to develop and institute specific plans to implement the recommendations. Follow up visits and telephone calls were made to the falls coordinator. Institution wide changes were recommended. Three 45 minute inservice education sessions were held for all patient care staff at each home.

\section{Main outcome measures}

Number of patients who had $\geqslant 2$ falls during follow up, number of injurious falls that required medical attention, decline in function, and death.

\section{Main results}

2013 recommendations were made for 211 patients; 1263 (63\%) were implemented at 3 months. The mean proportion of patients who fell repeatedly was lower in the study homes $(44 \%$ $v 54 \%, \mathrm{p}=0.03)$. The groups did not differ for mean rate of injurious falls (13.7 in the study group $v 19.9 / 100$ person-years in the control group, $p=0.22)$, mean change from baseline in resident functional status ( $\mathrm{p} \geqslant 0.09$ for each of 11 measures), and all cause mortality (23 $v 17$ deaths $/ 100$ person-years, $\mathrm{p}=0.28$ ).

\section{Conclusion}

A structured individualised intervention in nursing homes reduced the proportion of high risk patients who had recurrent falls.

Sources of funding: in part, Centers for Disease Control and Prevention; with equipment donations from North Coast Medical Inc, DeRoyal Industries Ottobock, and Orthopaedic Industry.

For article reprint: Dr WA Ray, Division of Pharmacoepidemiology, Department of Preventive Medicine, Vanderbilt University, School of Medicine, Nashville, TN 37232, USA. Fax +16153438722.

\section{Commentary}

The study by Ray et al is one of the first trials showing the effectiveness of a fall prevention programme for nursing home residents. Reduction of hazards in their environment was a major target for programme activities. An intervention component that was absent from this study was exercise. Previous research has shown that exercise programmes can be effective in reducing falls among seniors, ${ }^{1}$ and high resistance strength training leads to gains in muscle strength and functional mobility among frail, institutionalised seniors. ${ }^{2}$

Only 26 of 79 potentially eligible nursing homes were approached. It is not possible to establish the comparability of nursing homes included and excluded from the study. Study results are generalisable to ambulatory nursing home clients at highest risk of falls. It would be useful to know whether programme implementation had any positive spin offs for nursing home residents who were not eligible to receive the intervention.

Study results are relevant to nurse managers and staff nurses in long term care settings. Although the relative contributions of individual intervention components cannot be assessed, findings indicate that a multidisciplinary and multicomponent approach to lowering risk can decrease the rate of recurrent falls among high risk residents. However, 2 precautions are warranted. Firstly, only $63 \%$ of recommended safety measures were in place at 3 months, highlighting the challenge of compliance by the health provider when a large array of interventions are recommended. Selecting the most cost effective interventions among those implemented would be a useful step for others planning similar programmes. Secondly, use of physical restraint in the intervention homes substantially increased. Careful monitoring of restraint use in institutions adopting this programme should be part of quality control measures.
Finally, the positive results might be further strengthened by augmenting the intervention with other environmental structural changes such as contrast markings on stair edges, ${ }^{3}$ an efficacious exercise programme, and hip joint padding to attenuate the effect of serious falls. ${ }^{4}$

$$
\begin{array}{r}
\text { Nancy Edwards, RN, PhD } \\
\text { Associate Professor } \\
\text { School of Nursing, University of Ottawa } \\
\text { Ottawa, Ontario, Canada }
\end{array}
$$

1 Province MA, Hadley EC, Hornbrook MC et al. The effects of exercise on falls in elderly patients. A preplanned meta-analysis of the
FICSIT Trials. Frailty and injuries: cooperative studies of intervention techniques. JAMA studies of intervent

2 Fiatarone MA, Marks EC, Ryan ND et al. Highintensity strength training in nonagenarians. Effects on skeletal muscle. JAMA 1990;263: 3029-34.

3 Aminzadeh F. Stair hazards among seniors: hazards, safety recommendations, and building codes. Ottawa: Community Health Research Unit, 1996.

4 Lauritzen JB, Petersen MM, Lund B. Effect of external hip protectors on hip fractures. Lancet 1993;341:11-3. 